УДК 536.7 663.1: 663.4: 664

\title{
CREATION AND MAINTENANCE OF ENERGY-MASS EXCHANGE PROCESSES IN GAS-LIQUID ENVIRONMENTS
}

\author{
K. Vasylkivsky, I. Maksymenko, A. Chagaida, V. Piddubny, Yu. Stupak \\ National University of Food Technologies
}

\begin{tabular}{|c|c|}
\hline Key words: & ABSTRACT \\
\hline $\begin{array}{l}\text { aerobic fermentation, } \\
\text { gas-liquid media, } \\
\text { mass and energy exchange, } \\
\text { gas holding capacity, } \\
\text { oscillatory process }\end{array}$ & $\begin{array}{l}\text { The article deals with the peculiarities of creating and main- } \\
\text { taining energy and mass transfer processes in gas-liquid media } \\
\text { with different technologies of gas phase formation. } \\
\text { With regard to aerobic media, a list of processes that operate } \\
\text { in accordance with the laws of thermodynamics. }\end{array}$ \\
\hline $\begin{array}{l}\quad \text { Article history: } \\
\text { Received } 31.08 .2020 \\
\text { Received in revised form } \\
13.09 .2020 \\
\text { Accepted } 30.09 .2020\end{array}$ & $\begin{array}{l}\text { The analysis of features of interaction of liquid and gas phases } \\
\text { is given. } \\
\text { It is shown that the gas holding capacity of the medium is a } \\
\text { defining characteristic that forms both energy and power parame- } \\
\text { ters and the dynamics of mass transfer and energy exchange pro- }\end{array}$ \\
\hline $\begin{array}{l}\text { Corresponding author: } \\
\text { mif63@i.ua }\end{array}$ & $\begin{array}{l}\text { It is determined expedient to cool the compressed gas phase } \\
\text { in the processes of air preparation for the subsequent recovery } \\
\text { use in the modes of temperature stabilization of media in parallel } \\
\text { with the main technological task of oxygen delivery for the aero- } \\
\text { bic process. } \\
\text { Prospects for the intensification of mass transfer processes } \\
\text { under conditions of variable pressures over media with a gas pha- } \\
\text { se for the creation of oscillatory processes in such systems are } \\
\text { shown. } \\
\text { It is shown that the specific compression work and air tempe- } \\
\text { rature are nonlinear functions of the compression level of the gas } \\
\text { phase. } \\
\text { It is proved that isobaric cooling of compressed air is accom- } \\
\text { panied by significant energy costs, which in the range of pressure } \\
\text { changes from } 140 \text { to } 300 \text { kPa are from } 33 \text { to } 39 \% \text { of energy con- } \\
\text { sumption for adiabatic compression. } \\
\text { Assumptions about the equality of the Archimedean force and } \\
\text { the force of resistance of the medium in action on a single bubble } \\
\text { are logically transferred to the whole array of gas phase in the } \\
\text { medium. This action is a consequence of the manifestation of Ar- } \\
\text { chimedes' law or, more precisely, a manifestation of the combi- } \\
\text { nation of gravitational field and hydrostatic pressure. }\end{array}$ \\
\hline
\end{tabular}

DOI: $10.24263 / 2225-2916-2020-27-13$

(C) К. В. Васильківський, І. Ф. Максименко, А. О. Чагайда, В. А. Піддубний, Ю. О. Ступак, 2020 


\title{
СТВОРЕННЯ I ПІДТРИМАННЯ ЕНЕРГО- I МАСООБМІННИХ ПРОЦЕСІВ У ГАЗОРІДИННИХ СЕРЕДОВИЩАХ
}

\author{
К. В. Васильківський, канд. техн. наук \\ І. Ф. Максименко, інженер \\ А. О. Чагайда, канд. техн. наук \\ В. А. Піддубний, д-р техн. наук \\ Ю. О. Ступак \\ Національний університет харчових технологій
}

Стаття стосується особливостей створення і підтримання енерго- і масообмінних процесів у газорідинних середовищах з різними технологіями утворення газової фрази. Стосовно аеробних середовищ сорормульовано перелік процесів, які діють відповідно до законів термодинаміки. Наведено аналіз особливостей взаємодії рідинних і газових фраз. Показано, що газоутримувальна здатність середовища $\epsilon$ визначальною характеристикою, яка фрормує одночасно енергетичні та силові параметри і динаміку масообмінних та енергообмінних процесів. Визначено доцільним у процесах підготовки повітря охолоджувати стиснуту газову фразу для наступного рекупераційного використання в режимах температурної стабілізації середовищ паралельно з основним технологічним завданням доставки кисню для аеробного процесу. Показано перспективи інтенсифрікації масообмінних процесів в умовах змінних тисків над середовищами з газовою фазою для створення в таких системах коливальних процесів.

Ключові слова: аеробне бродіння, газорідинні середовища, масо- та енергообмін, газоутримувальна здатність, коливальний процес.

Постановка проблеми. Аналіз значної кількості технологічних процесів харчової і мікробіологічної промисловостей приводить до висновку про доцільність зіставлення в них ефективності перехідних процесів та усталених режимів. Виконання таких завдань потребує комплексного врахування особливостей утворення середовищ, енергетичних і матеріальних балансів, законів та положень технічної термодинаміки. За рівнем насичення і кількості основних процесів та процесів технічного забезпечення, в тому числі за нестаціонарних початкових умов, на увагу заслуговують технології, пов'язані з аеробним синтезом мікроорганізмів. У загальному переліку потреб до останніх відносяться такі складові:

- забирання із зовнішнього середовища повітря, його фізична й асептична підготовка та стискання до значень, які нададуть можливість вхідному газовому потоку подолати гідростатичний тиск рідинної фази на рівні координати введення. Наслідком стискання повітря буде підвищення його температури, енергетичного потенціалу та зменшення об'єму. Швидкоплинність перебігу стискання дає змогу вважати його наближеним до рівня адіабатного процесу і це означає, що кінцева температура $\mathrm{T}_{(\kappa)}$ залежить від початкової $\mathrm{T}_{(\text {п) }}$ i кінцевого тиску. При цьому значення $\mathrm{T}_{(\kappa)}$ обмежуються технологічними умовами і нестворенням температурних шоків щодо мікроорганізмів;

- ізобарне охолодження стиснутого повітря з метою стабілізації його температури на номінальному рівні, у тому числі з урахуванням необхідного рівня охолодження рідинної фази в режимі відведення теплоти бродіння; 
- диспергування газового потоку в рідинній фазі середовища з утворенням міжфазної поверхні, що є залежним від фізико-хімічних властивостей фаз, швидкостей їх контактування, потужності вхідного газового потоку;

- перехідний і усталений режими формування структури газорідинної системи, стабілізація газоутримувальної здатності й утворення циркуляційних контурів;

- масообмін на поверхні поділу фаз за наявності зустрічних потоків $\mathrm{CO}_{2}$ і $\mathrm{O}_{2}$ та мікроциркуляції $\mathrm{N}_{2}$ у зв'язку з впливом гідростатичного тиску і утворенням концентраційних градієнтів;

- ізотермічне розширення диспергованої газової фази з охолодженням середовища.

Мета дослідження: комплексна оцінка енергетичних і матеріальних трансформацій у процесах взаємодії газових та рідинних складових систем аеробного бродіння.

Матеріали і методи дослідження - теоретичне дослідження на основі феноменологічного аналізу перебігу процесів трансформацій газових потоків і газорідинних систем з урахуванням їх взаємодії і переходом до рівнів об'ємних напружених станів.

Результати дослідження. Наведений перелік процесів і ефектів взаємодії газової та рідинної фаз за наявності мікробіологічних клітин і їх участі у енерго- і масообмінних процесах є динамічним комплексом, відносно якого до нашого часу вирішено лише окремі локальні задачі в пошуках удосконалення технологій і результативності з точки зору продуктивності, виходу біологічної продукції та ії якісних показників [1-4]. Прикладом недосконалості оцінки і спроб моделювання гідродинамічних режимів в газорідинних середовищах є відсутність аналізу впливів їх геометричних параметрів в ізооб' ємних апаратах [5-7]. Разом з тим першим питанням в таких умовах $\epsilon$ інтенсивність режимів формування газової фази або аерації, якщо в систему газова вводиться примусово. Пропозиція ж моделювати ситуацію кількістю (об'ємом) газової фази, що за одиницю часу вводиться на $1 \mathrm{~m}^{3}$ рідинної фази, не може бути прийнятою через відмінності у співвідношеннях висоти середовища і площі його поперечного перерізу. Нівелювати впливи таких співвідношень можливо, використовуючи для оцінки інтенсивності аерації показник приведеної швидкості газової фази. Остання, як відомо, визначається відношенням потоку газової фази, що подається в середовище в $\mathrm{m}^{3} / \mathrm{c}$, до площі поперечного перерізу в м². Виконання такої умови означає рівність енергетичних витрат в ізооб'ємних апаратах з подоланням відповідних гідростатичних тисків [8; 10].

Вказаний процес аерації має кілька складових термодинамічних трансформацій, відносно яких виникає необхідність чіткого вибору при їх визначенні. Так, стискання вхідного газового потоку в компресорі запропоновано вважати адіабатним, хоча такий вибір все-таки потребує деяких пояснень. Очевидно, що стискання газового потоку означає введення в нього енергії, еквівалентної роботі стискання. Підвищення енергії газового потоку означає зростання його температури, яке не може не відобразитися на температурах циліндра і поршня компресора (або робочих елементів турбокомпресора). Це супроводжується усталеним режимом теплопередачі у навколишнє середовище і частковою втратою енергії газового потоку, у зв'язку з чим стискання останнього може вважатися лише деяким наближенням до адіабатного процесу. При цьому ступінь такого наближення залежить від швидкості 
перебігу стискання і часу перебування стиснутого потоку в контакті з навколишнім середовищем, геометрії повітроводів і поверхні контактування.

Віднесення стискання повітря до адіабатного процесу дає змогу визначити всі кінцеві термодинамічні параметри за умови відомих початкових значень тиску і температури [11].

Очевидно, що вказані початкові параметри не будуть стабілізованими, як і параметри навколишнього середовища, а діапазон їх відхилення повинен ураховуватися у зв'язку з обмеженнями нестабільності температур на вході в культуральне середовище.

Наступна термодинамічна операція пов’язана з охолодженням газового потоку в режимі ізобарного процесу. Вона має подвійне призначення як з точки зору інтересів відведення з системи теплоти біологічного синтезу, так і з точки зору можливості стабілізації температури вхідного в технологічний апарат повітряного потоку.

Кількість відведеної теплоти визначається величиною масового потоку газової фази, що проходить через культуральне середовище, його теплоємкістю і різницею кінцевої та початкової температур. Відповідно до теплового балансу кількості відведеної теплоти і теплоти біологічного синтезу між собою рівні, а ознакою такої рівності є стабілізована температура культурального середовища.

Номінальна температура культивування мікроорганізмів є відомою, що дає змогу визначити можливий діапазон в межах $\mathrm{T}_{\min }$ i $\mathrm{T}_{\max }$. При цьому початковим умовам $\mathrm{P}_{1}$ i $\mathrm{T}_{1}$ відповідають залежності $\mathrm{T}_{2 \max }=\mathrm{T}_{2 \max }\left(\mathrm{P}_{\max }\right)$ i $_{2 \min }=\mathrm{T}_{2 \min }\left(\mathrm{P}_{\min }\right)$. Тобто для адіабатного процесу маємо:

Звідси

$$
\begin{aligned}
& \mathrm{T}_{2 \max }=\mathrm{T}_{1}\left(\frac{\mathrm{P}_{2 \max }}{\mathrm{P}_{1}}\right)^{\frac{\mathrm{k}-1}{\mathrm{k}}} . \\
& \mathrm{P}_{2 \frac{\max }{\min }}=\mathrm{P}_{1} \sqrt[\frac{\mathrm{k}-1}{\mathrm{k}}]{\frac{\mathrm{T}_{2 \frac{\max }{\min }}}{\mathrm{T}_{1}}} .
\end{aligned}
$$

Оскільки маємо поєднання адіабатного та ізобарного процесів, що виконуються в обумовленій послідовності, то доцільно оцінити діапазони змін початкових термодинамічних параметрів. Значення величин $\mathrm{P}_{1}$ відповідають барометричним тискам і тому їх відхилення від середніх значень вкладаються в межі $2 \ldots 4 \%$, тоді як значення початкових температур можуть мати добові відхилення $15 \ldots 20^{\circ} \mathrm{C}$, а сезонні $-50 \ldots 60^{\circ} \mathrm{C}$. Прогнозовані впливи цих відхилень мають враховуватися в системах стабілізації температур. Графічне відображення взаємозв'язків параметрів наведено на рис. 1.

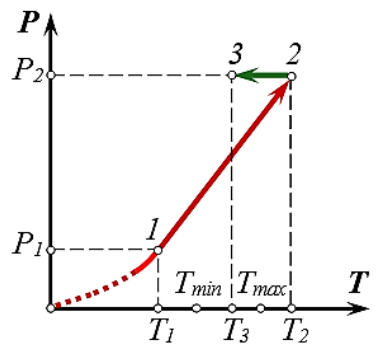

Рис. 1. Діаграма залежності $\mathrm{P}=\mathrm{P}(\mathrm{T})$ відображення процесів адіабатного стискання та ізобарного охолодження повітря в системах аерації культуральних середовищ для вирощування мікроорганізмів 
Початковим параметрам $\mathrm{P}_{1}$ та $\mathrm{T}_{1}$ на діаграмі $\mathrm{P}-\mathrm{T}$ відповідає точка 1 , а адіабатне стискання повітря відображено відрізком $1-2$. Точці 2 , що відповідає завершенню цього стискання, відповідають параметри $\mathrm{P}_{2}$ та $\mathrm{T}_{2}$. Оскільки значення $\mathrm{T}_{2}$ перевищує допустимий параметр $T_{\max }$, то це означає необхідність охолодження газової фази, що відображується на діаграмі відрізком 2-3. Цей процес є ізобарним, оскільки має виконуватися умова

$$
\mathrm{P}_{2}>\text { ggh }+\mathrm{P}_{0}, \text { Па, }
$$

де $\rho$ - питома маса рідкого культурального середовища, кг/м³ $; \mathrm{g}-$ прискорення вільного падіння, м/ $/ \mathrm{c}^{2} ; \mathrm{h}$ - висота рідинної фази, м.

Положення точки 3 на ізобарі обирається одночасно на ізотермі, початок якої відповідає значенню $\mathrm{T}_{3}$ в межах величин $\mathrm{T}_{\min } \mathrm{i} \mathrm{T}_{\max }$.

Наступною технологічною й одночасно термодинамічною операцією $є$ матеріальна трансформація безперервного газового потоку з утворенням в рідинній фазі диспергованої газової фази. Її здійснення досягається барботажним процесом, а енергетичний потенціал забезпечується трансформацію кінетичної енергії газових потоків. При цьому мають місце енергоматеріальні зміни двох видів.

По-перше, досягається утворення диспергованої газової фази і енергетичні витрати стосуються утворення міжфазної поверхні F:

$$
\mathrm{E}_{\mathrm{F}}=\sigma \mathrm{F}, \text { Дж }
$$

де $\sigma$ - коефіцієнт поверхневого натягу, Дж/м².

Потужність газового потоку визначається його масовою характеристикою i швидкістю:

$$
\mathrm{W}_{\text {кін }}=\mathrm{m} \frac{\mathrm{V}^{2}}{2}, \text { Вт, }
$$

де $\mathrm{m}$ - масовий потік газу, кг/c.

Диспергування вхідного газового потоку можливо оцінювати суто механічним процесом, на який накладається енергетична трансформація у двох формах. Це, як відмічалося, стосується енерговитрат на утворення міжфазної поверхні і, по-друге, при розбіжності температур рідинної фази і стиснутого повітря має відбутися їх вирівнювання.

Феноменологічні міркування приводять до висновку, що вирівнювання температур у зв'язку зі значним рівнем дисперсності фази має відбутися достатньо швидкоплинно за відносно обмежених змін швидкостей спливання газової фази в обмежених координатах. Це означає, що енергообмін у таких умовах може вважатися ізобарним процесом. Вирівнювання температур у цих умовах означає початок режиму охолодження рідинної фази. В основі швидкоплинності цієї частини енергообміну лежить високий рівень турбулентності газорідинного середовища. Останнє накладає відбиток на цю локальну зону і на перехідний процес спливання газової фази. Однак очікувана ефективність теплообміну за час перебування бульбашок в цій зоні приводить до вирівнювання температур. Від цього моменту газова фаза має вважатися такою, яка перебуває в ізотермічних умовах. У наступному процесі спливання диспергована газова фаза у зв'язку зі зниженням гідростатичного тиску розширюється, що забезпечує подальший перебіг процесу охолодження культурального середовища. 
На основі останніх міркувань маємо можливість продовжити побудову графіків процесів в координатах $\mathrm{P}-\mathrm{T}$ (рис. 2).

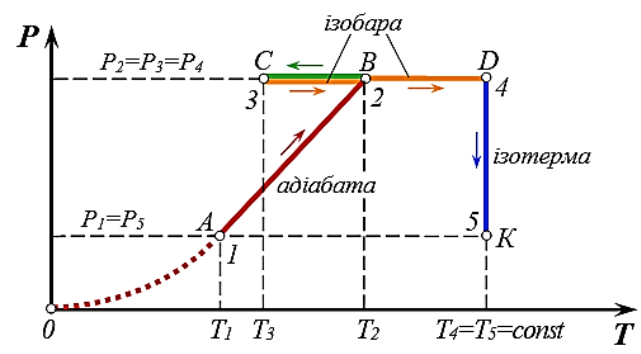

Рис. 2. Діаграма термодинамічних трансформацій газової фази в процесах аерації культуральних середовищ в координатах $\mathbf{P}-\mathbf{T}$ : $1-2-$ адіабатне стискання повітря компресором; 2-3 - ізобарне охолодження стиснутого повітря; $3-4-$ ізобарне нагрівання диспергованої газової фази в період утворення міжфазної поверхні; 4-5 - ізотермічне розширення диспергованої газової фази

Загальне розташування діаграми в площині координат Р-Т залежить від початкових координат точки А. Якщо технологічний апарат виконано негерметичним, то протитиск у ньому відсутній. Це означає, що за показниками тиску початкова i кінцева координати збігаються.

Функціональне навантаження щодо охолодження середовища досягається в ізобарному процесі, пов'язаному з утворенням диспергованої газової фази та в ізотермічному процесі розширення останньої. Розширення газової фази пов'язане з їі спливанням і відповідним зниженням гідростатичного тиску.

В окремих випадках [1-5] з метою інтенсифікації масообмінних процесів здійснюються пульсації тисків газової фази над об'ємом газорідинного середовища. Такі пульсації знаходять відповідне й еквівалентне відображення в кожній довільно обраній зоні середовища і сприяють активному оновленню міжфазної поверхні в їі змінах. Проте зміна розмірів і об' ємів диспергованої газової фази є далеко не єдиним результатом відгуку системи на зміни тисків. Вторинним результатом у зв'язку зі змінами об'єму газової фази мають бути зміни газоутримувальної здатності середовища, загальної гідродинаміки, пов'язаної з циркуляційними контурами, абсолютної швидкості спливання газової фази тощо. У загальному випадку наявність змінних тисків на діаграмі $\mathrm{T}=\mathrm{T}(\mathrm{V})$ має відобразитися на ізотермі $4-5$ і визначати коливальні зміни газоутримувальної здатності (рис. 3).

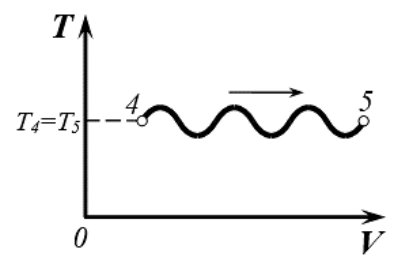

Рис. 3. Діаграма до змін газоутримувальної здатності залежно від $\mathrm{P}_{0}=\mathrm{P}_{0}(\tau)$, де $\tau$ - час перебігу процесу

При цьому відхилення температури Т є мінімізованими, оскільки процес залишається наближеним до ізотермічного, хоча залежно від швидкості зміни тиску 
$\mathrm{P}_{0}=\mathrm{P}_{0}(\tau)$ в ньому можна помітити ознаки адіабатного процесу. Очевидно, що при цьому певна роль належить і закону зміни зовнішньому для системи тиску. Наявність останніх має прояв на молекулярному рівні масообміну, пов'язаному із законом Генрі і розчинністю газів.

Відомо, що аерація культуральних середовищ пов' язана з таким переліком завдань:

- забезпечення аеробного режиму синтезу біомаси доставкою кисню в середовище;

- відведення синтезованого діоксиду вуглецю;

- відведення теплоти біологічного синтезу і стабілізація температурних параметрів системи;

- гомогенізація середовища.

Тож на особливості термодинамічних трансформацій газової фази в різних формах накладаються більш тонкі процеси масо- і теплообміну, синтезу біомаси, фізико-хімічні характеристики середовищ, показники осмотичних тисків зокрема.

Оцінку взаємовпливів названих параметрів можливо здійснювати на комплексному врахуванні їх наявності. Очевидно, що динаміка генерування біологічної теплової енергії закладається технологічною схемою, в основу якої покладається певний біологічний параметр. Останнім може бути швидкість приросту біомаси за відомої ії концентрації. Це означає можливість визначення динаміки споживання живильних речовин, енерговиділення споживання розчиненого кисню, утворення діоксиду вуглецю.

Стабілізація температурних параметрів може здійснюватися завдяки використанню різних технологічних прийомів. Це може досягатися використанням сорочок охолодження або охолодженням притоку води з компонентами живлення або за рахунок досліджуваної в цій роботі системи. Очевидно, що придатними до використання можуть бути і комбінації з різних систем. Однак необхідність стискання аераційного повітря дає змогу використати термодинамічні наслідки цього процесу саме для охолодження культуральних середовищ.

Важливою перевагою у випадку останнього вибору є можливість досягнення стабілізації температури культурального середовища без використання проміжних матеріальних носіїв теплових потоків. Очевидно, що підвищення температури повітря в режимі його стискання в адіабатному процесі надає можливість охолодити його наближено до початкової температури навколишнього середовища.

Сполучення ідеалізованих газових трансформацій приводять до послідовного переліку: адіабатного стискання повітря; ізобарного охолодження, ізобарного нарівання, ізотермічного розширення.

Для можливості оцінки впливу різних початкових і кінцевих умов на кінцеві параметри системи виконаємо розрахунки з визначення кінцевої температури, роботи стискання, зміни внутрішньої енергії та ентропію для 1 кг повітря. Показник адіабати приймемо $\mathrm{k}=1,4$.

Нехай початковий тиск повітря складає $\mathrm{p}_{1}=100$ кПа, температура $-\mathrm{t}=27^{\circ} \mathrm{C}$, кінцевий тиск приймемо 3 градацією 4 м в.ст., тобто $\mathrm{p}_{2}=140 ; 180 ; 220 ; 260 ; 300$ кПа. При цьому початковий об' єм газової фази складає $0,861 \mathrm{~m}^{3}$.

Результати розрахунків представлено у вигляді графіків на рис. 4-8. 


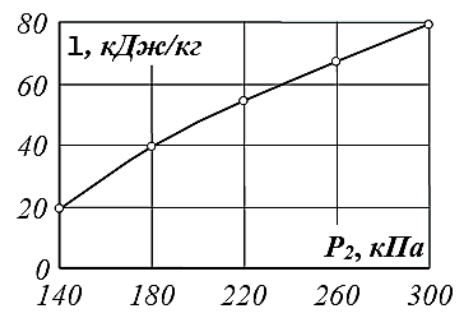

Рис. 4. Графік залежності роботи стискання 1 кг повітря від $P_{1}=100$ кПа до значення $\mathbf{P}_{2}$

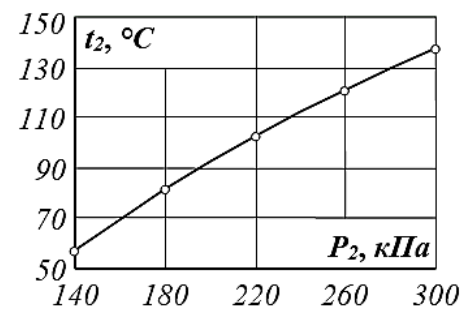

Рис. 5. Графік залежності температури стиснутого газу при $\mathrm{t}_{1}=27^{\circ} \mathrm{C}$ і $P_{1}=100$ кПа від кінцевого тиску $P_{2}$

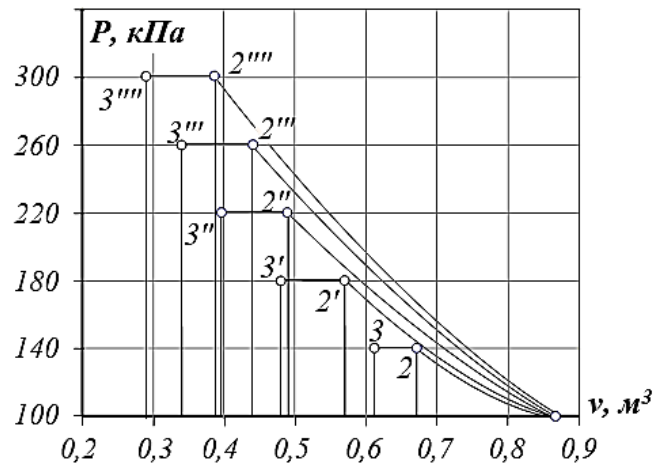

Рис. 6. Графік залежності $p=p(v)$ для етапів адіабатного стискання та ізобаричного охолодження до $\mathrm{t}=303 \mathrm{~K}$

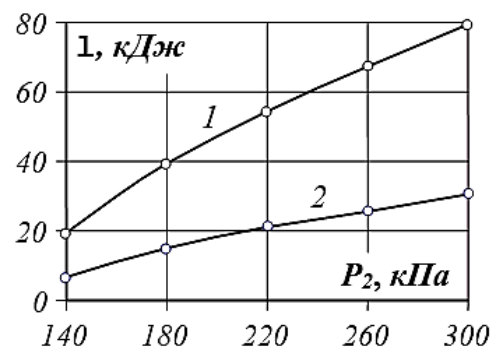

Рис. 7. Графік роботи адіабатного стискання повітря (1) та роботи на підтримання тиску за ізобаричного охолодження (2)

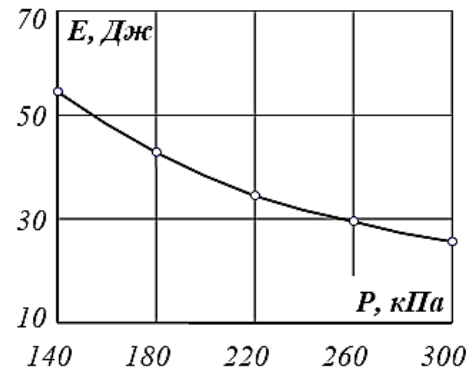

Рис. 8. Графік залежності енергії створення міжфазної поверхні від тисків

Висновки. 3 наведених графічних узагальнень результатів розрахунків випливає:

- в адіабатному процесі стискання внутрішня енергія повітря зростає і чисельно дорівнює роботі стискання. Питома робота стискання і температура повітря $\epsilon$ нелінійними функціями рівня стискання газової фази. При цьому чисельні значення температур навіть за риску 140 кПа і тим паче за 180 кПа вказують на необхідність 
охолодження газових потоків за умови оптимальних температур життєдіяльності мікроорганізмів;

- ізобаричне охолодження стиснутого повітря супроводжується помітними енергетичними витратами, які в межах змін тиску від 140 до 300 кПа складають від 33 до 39\% енерговитрат на адіабатне стискання і одночасно дає змогу організовувати температурну стабілізацію середовищ на рекуперативному рівні;

- рівень дисперсності газової фази, що утворюється в процесі взаємодії вхідного повітряного потоку і рідинної фази, залежить від швидкості їх контактування. У зв’язку з останнім рекомендується вибір геометричних і кінематичних параметрів здійснювати таким, щоб забезпечувати вказану швидкість контактування $25 \ldots 30$ м/с.

- в ізотермічному процесі спливання газової фази у зв'язку з розширенням останньої має місце висотне збільшення газоутримувальної здатності середовища i зростання загального рівня об'ємного напруженого стану.

\title{
ЛITEРАТУРА
}

1. Соколенко А. I. Енергоматеріальні трансформації в харчових технологіях на основі замкнутих контурів / Соколенко А. І., Чагайда А. О., Піддубний В. А. — Київ: Кондор, 2015. $300 \mathrm{c}$.

2. Інтенсифікація тепло- масообмінних процесів в харчових технологіях / Соколенко А. I. та ін. - Київ: Фенікс, 2011. - 536 с.

3. Sokolenko A. Process parameters of aerobic synthesis of microorganisms / Sokolenko A., Koval O. // Scientific development and achievements. - 2018. - Volume 5. - P. 319-333.

4. Соколенко А. І. Енергетичні імпульси в харчових технологіях / А. І. Соколенко, А. А. Палаш, І. Ф. Максименко // Наукові праці НУХТ. — 2012. — № 47. — С. 73 -78.

5. Лензіон С. В. Розвиток методів розрахунку і обладнання транспортно-технологічних систем у виробництві шампанських вин: дис. ... канд. техн. наук: 05.18.12. / Лензіон С. В. Київ: НУХТ, $2011 .-167$ с.

6. Mandal A. Characterization of gas-liquid parameters in a down-flow jet loop bubble column / A. Mandal // Brazilian Journal of Chemical Engineering. - 2010. - 27(2), DOI: 10.1590/S010466322010000200004 .

7. Піддубний В. А. Наукові основи і апаратурне оформлення перехідних процесів харчових і мікробіологічних виробництв: дис. ... докт. техн. наук: 05.18.12. / Піддубний В. А. — Київ: НУХТ. 2007. $-421 \mathrm{c}$.

8. Коваль О. В. Удосконалення процесів і модернізація обладнання бродильних виробництв: дис. ... канд. техн. наук: 05.18.12. Коваль О. В. - Київ: НУХТ. 2016. 174 с.

9. Енергетичні потенціали газорідинних середовищ / Соколенко А. І. та ін. // Наукові праці НУХТ. - 2018. - Том 24, № 1. - С. 108-118.

10. Шевченко О. Ю. Наукові основи і апаратурне оформлення процесів довгострокового зберігання харчових продуктів: автореф. дис. ... докт. техн. наук: 05.18.12. / Шевченко О. Ю. Київ: НУХТ. 2006. - 43 с.

11. Буляндра О. Ф. Збірник задач з технічної термодинаміки / Буляндра О. Ф. — Київ: НУХТ, 2015. - $394 \mathrm{c}$.

\section{СОЗДАНИЕ И ПОДДЕРЖАНИЕ ЭНЕРГО- МАССООБМЕННЫХ ПРОЦЕССОВ В ГАЗОЖИДКОСТНЫХ СРЕДАХ}

\author{
К. В. Васильковский, И. Ф. Максименко, \\ А. О. Чагайда, В. А. Поддубный, Ю. А. Ступак \\ Национальный университет пищевых технологий
}

Статья касается особенностей создания и поддержания энерго- и массообменных процессов в газожидкостных средах с различными технологиями образования газовой фразы. Относительно аэробных сред сфрормулирован перечень процессов, 
которые действуют в соответствии с законами термодинамики. Приведен анализ особенностей взаимодействия жидкостных и газовых фраз. Показано, что газоудерживающая способность среды является определяющей характеристикой, фрормирует одновременно энергетические и силовые параметры и динамику массообменных и энергообменных процессов. В процессах подготовки воздуха доказана целесообразность охлаждения сжатой газовой фразы для последующего рекуперационного использования в режимах температурной стабилизации сред параллельно с основным технологическим заданием доставки кислорода для аэробного процесса. Показаны перспективы интенсификации массообменных процессов в условиях переменных давлений над средами с газовой фразой для создания в таких системах колебательных процессов.

Ключевые слова: аэробное брожение, газожидкостные среды, массо- и энергообмен, газоудерживающая способность, колебательный процесс. 